\title{
Samarium diiodide promoted coupling of thiophenecarbaldehydes
}

\author{
Shyh-Ming Yang and Jim-Min Fang* \\ Department of Chemistry, National Taiwan University, Taipei, Taiwan 106, Republic of China
}

Thiophene-2-carbaldehyde adds to aromatic and aliphatic aldehydes with the mediation of samarium diiodide and hexamethylphosphoramide. These hydroxyalkylations occur at the 5-position of thiophene-2carbaldehyde. The self- and cross-coupling reactions of thiophene-3-carbaldehyde occur at the 2-position. $S$-Alkylation of the reaction intermediates gives substituted $\gamma$-lactols.

Thiophenecarbaldehydes are generally reduced to the thiophenemethanols by catalytic hydrogenation ${ }^{1}$ or by treatment with $\mathrm{LiAlH}_{4}{ }^{2}$ or $\mathrm{Fe}-\mathrm{HOAc}{ }^{3}$ On treatment with $\mathrm{Mg}-\mathrm{MgI}_{2}$ thiophenecarbaldehydes undergo self-coupling to give pinacols. $^{4}$ Electrochemical reductions of acetylthiophene or benzoylthiophene also give pinacols. ${ }^{5}$ Reductions of alkanoylthiophenes with dissolved metals such as $\mathrm{Li}-\mathrm{NH}_{3}$ or $\mathrm{Na}-\mathrm{NH}_{3}$ give the 2,5-dihydro derivatives. ${ }^{6}$ However, reductions of thiophenes to tetrahydrothiophenes are achieved with $\mathrm{Et}_{3} \mathrm{SiH}-$ $\mathrm{CF}_{3} \mathrm{CO}_{2} \mathrm{H}^{7}$ We demonstrated previously that bimolecular reduction of benzaldehydes ${ }^{8}$ or indolecarbaldehydes, ${ }^{9}$ by way of aryl-carbonyl couplings, occur with $\mathrm{SmI}_{2}$ in the presence of hexamethylphosphoramide (HMPA) whereas pinacol couplings are diminished under these conditions. We report herein the self- and cross-coupling of thiophenecarbaldehydes 1 and 2 promoted by $\mathrm{SmI}_{2}-\mathrm{HMPA}$. The thiophene-carbonyl coupling products were trapped with halogenalkanes and the products were elaborated to butenolides.

As shown in Table 1, acceptor substrates include benzaldehydes 3 and 6, a pyrrolecarbaldehyde 4 and an aliphatic aldehyde 5. The cross-coupling of thiophene-2-carbaldehyde and thiophene-3-carbaldehyde (entry 2) gave a product 8 , indicating the former aldehyde served as the donor whereas the latter aldehyde served as the acceptor. The reactions occurred via thiophene-carbonyl couplings although small amounts of products such as $\mathbf{1 3}$ and 19 derived from pinacol couplings were also found (entries 6 and 8). The pinacol of thiophene-3-carbaldehyde and 1-methylpyrrole-2-carbaldehyde might transfer a hydride to thiophene-3-carbaldehyde, so that both the reductive product, 3-thienylmethanol 18, and the oxidative product, 19, were obtained in nearly equal amounts.

Oxidation of alcohols 7-11 with pyridinium dichromatemolecular sieves (PDC-MS) gave the corresponding solid ketones 20-24. The intermediate in the self-coupling of thiophene-3-carbaldehyde was trapped with benzyl bromide to give lactol 25 (65\%, two epimers), which was transformed into lactone $26(79 \%)$ on treatment with PDC-MS (Scheme $1)$. The intermediate in the cross-coupling of thiophene-3carbaldehyde and 4-methoxybenzaldehyde also underwent $S$-alkylation. The reaction mechanism presumably involved sequential electron-transfer from $\mathrm{SmI}_{2}$ (2 equiv.) to thiophene3-carbaldehyde, giving an organosamarium intermediate $\mathbf{B}$, which was stabilised synergetically by the adjacent sulfur atom and by co-ordination with the oxygen ion.

Thiophenecarbaldehydes are conventionally converted into the corresponding $\alpha$-amino alkoxides ${ }^{10}$ which react with electrophiles to give substituted thiophenecarbaldehydes. This one-pot reaction requires, however, sequential treatment with amine (such as $N$-methylpiperazine) and BuLi (several molar proportions) at low temperatures. The regiochemistry of the reaction varies depending on the reaction conditions. Our

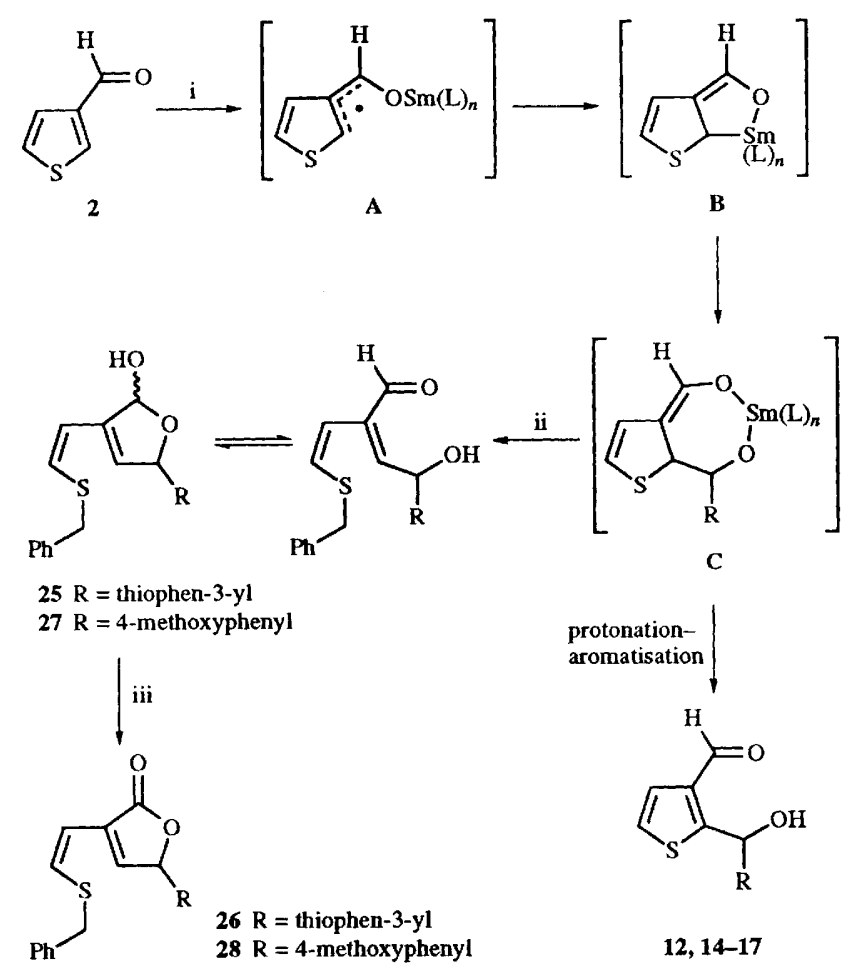

Scheme 1 Reagents and conditions: i, 2 ( $2 \mathrm{mmol}$ ) or 2 (1 $\mathrm{mmol})-\mathrm{RCHO}$ (1.2 mmol), $\mathrm{SmI}_{2}(3.65 \mathrm{mmol}), \operatorname{THF}\left(42 \mathrm{~cm}^{3}\right), \mathrm{HMPA}(16 \mathrm{mmol}), 0^{\circ} \mathrm{C}$, $10 \mathrm{~min}$; ii, $\mathrm{PhCH}{ }_{2} \mathrm{Br}(2 \mathrm{mmol}), 0$ to $27^{\circ} \mathrm{C}, 25 \mathrm{~h}$; iii, PDC, MS (4 $\AA$ ), $\mathrm{CH}_{2} \mathrm{Cl}_{2}, 27^{\circ} \mathrm{C}, 3-8$ h; yiclds: 25,$65 ; 26,79 ; 27,63 ; 28,70$

present method is relatively simple and gives products with predictable regiochemistry. The $\mathrm{SmI}_{2}$-promoted thiophenecarbonyl coupling is likely to be applicable to acetylthiophenes $\dagger$ of which hydroxyalkylations cannot be realised by the conventional methods.

\section{Experimental}

\section{General procedure}

Under an atmosphere of argon, Sm (660 mg, $4.4 \mathrm{mmol})$ and 1,2-diiodoethane $(1.03 \mathrm{~g}, 3.65 \mathrm{mmol})$ were stirred in anhydrous tetrahydrofuran (THF, $40 \mathrm{~cm}^{3}$ ) until a dark blue solution formed. HMPA $\left(2.8 \mathrm{~cm}^{3}, 16 \mathrm{mmol}\right)$ was added and then the solution was cooled to $0{ }^{\circ} \mathrm{C}$, after which a mixture of thiophene2-carbaldehyde (the donor substrate, $0.094 \mathrm{~cm}^{3}, 1.0 \mathrm{mmol}$ ) and

$\uparrow \mathrm{SmI}_{2}-\mathrm{HMPA}$ promoted dimerisation of acetophenone (phenylcarbonyl coupling) was reported in ref. 8 . 
Table 1 Coupling of thiophenecarbaldehydes promoted by $\mathrm{SmI}_{2}$ in THF and HMPA

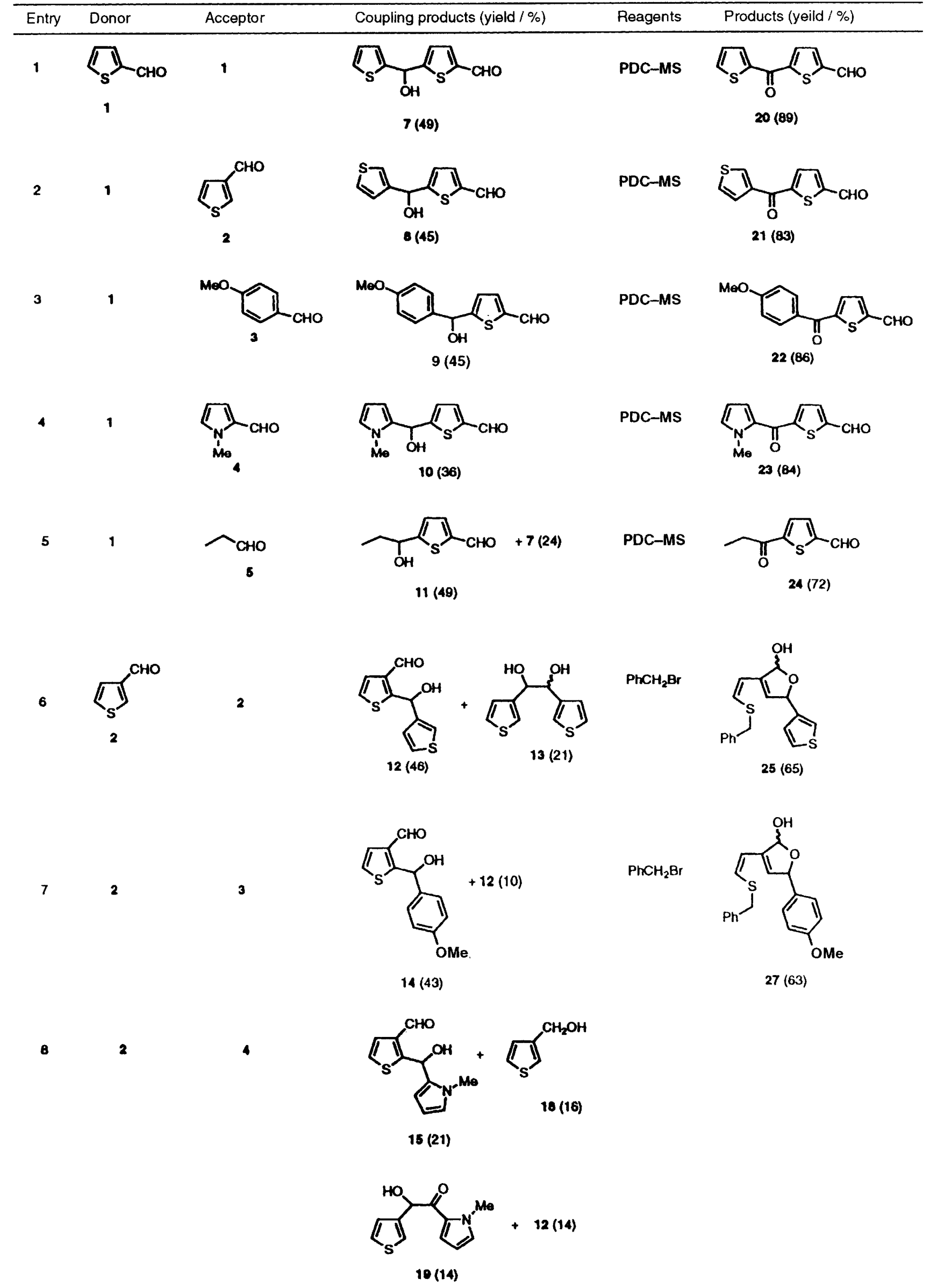


Table 1 (contd)

\begin{tabular}{llll}
\hline Entry Donor & Acceptor & Reagents \\
\hline & Products (yeild /\%) & \\
10 &
\end{tabular}

4-methoxybenzaldehyde (the acceptor substrate, $0.146 \mathrm{~cm}^{3}, 1.2$ mmol) in THF $\left(2 \mathrm{~cm}^{3}\right)$ were added dropwise. The mixture was stirred for $10 \mathrm{~min}$ at $0^{\circ} \mathrm{C}$ and $30 \mathrm{~min}$ at room temperature $\left(27^{\circ} \mathrm{C}\right)$. The reaction was quenched by the addition of saturated aqueous $\mathrm{NH}_{4} \mathrm{Cl}$, and the mixture was filtered through a pad of silica gel to remove HMPA. The residue was concentrated and chromatographed on a silica gel column by elution with EtOAc-hexane (2:8) to give the product $9(102 \mathrm{mg}, 45 \%)$. About $10-20 \%$ of the thiophene-2-carbaldehyde was recovered.

The coupling reactions of thiophene-3-carbaldehyde was carried out by similar procedures. In entries 6 and 7, the intermediates obtained by addition of the appropriate aldehyde at $0^{\circ} \mathrm{C}$ for $10 \mathrm{~min}$, were treated with benzyl bromide $\left(0.224 \mathrm{~cm}^{3}\right.$, $2.0 \mathrm{mmol})$ for $24 \mathrm{~h}$ at room temperature $\left(27^{\circ} \mathrm{C}\right)$ to give lactols $25(205 \mathrm{mg}, 65 \%)$ and $27(213 \mathrm{mg}, 63 \%)$, respectively, after the usual work-up.

All new compounds had compatible IR, mass, high-resolution mass, ${ }^{1} \mathrm{H}$ and ${ }^{13} \mathrm{C}$ NMR spectra. Some pertinent data are listed: 8, $\delta_{\mathrm{H}}\left(200 \mathrm{MHz} ; \mathrm{CDCl}_{3} ; J / \mathrm{Hz}\right) 9.80(1 \mathrm{H}, \mathrm{s}), 7.61(1 \mathrm{H}, \mathrm{d}, J 3.8)$, $7.33-7.29(2 \mathrm{H}, \mathrm{m}), 7.06(1 \mathrm{H}, \mathrm{dd}, J 4.6,1.6), 6.99(1 \mathrm{H}, \mathrm{d}, J 3.8)$, $6.10(1 \mathrm{H}, \mathrm{s}), 2.96(1 \mathrm{H}$, br s, OH $) .12, \delta_{\mathrm{H}}\left(200 \mathrm{MHz} ; \mathrm{CDCl}_{3}\right.$; $J / \mathrm{Hz}) 9.92(1 \mathrm{H}, \mathrm{s}), 7.43(1 \mathrm{H}, \mathrm{d}, J 5.1), 7.27(2 \mathrm{H}, \mathrm{m}), 7.20(1 \mathrm{H}, \mathrm{d}$, $J 5.1), 7.08(1 \mathrm{H}, \mathrm{dd}, J 4.4,1.9), 6.42(1 \mathrm{H}, \mathrm{d}, J 4.9), 4.43(1 \mathrm{H}, \mathrm{d}$, $J 4.9, \mathrm{OH}) .14, \delta_{\mathrm{C}}\left(50 \mathrm{MHz} ; \mathrm{CDCl}_{3}\right) 186.0(\mathrm{~d}), 159.6(\mathrm{~s}), 159.5$ (s), 136.1 (s), 133.9 (s), 129.8 (d), 127.9 (d, 2 C), 124.2 (d), 113.8 (d, 2 C), 70.2 (d), 55.2 (q). 15, $\delta_{\mathrm{H}}\left(200 \mathrm{MHz} ; \mathrm{CDCl}_{3} ; J / \mathrm{Hz}\right) 9.86$ $(1 \mathrm{H}, \mathrm{s}), 7.46(1 \mathrm{H}, \mathrm{d}, J 5.2), 7.22(1 \mathrm{H}, \mathrm{d}, J 5.2), 6.60(1 \mathrm{H}, \mathrm{dd}$, $J 2.7,1.8), 6.37(1 \mathrm{H}, \mathrm{d}, J 5.7), 5.99(1 \mathrm{H}, \mathrm{dd}, J 3.6,2.7), 5.86(1 \mathrm{H}$, dd, $J 3.6,1.8), 4.15(1 \mathrm{H}, \mathrm{d}, J 5.7, \mathrm{OH}), 3.68(3 \mathrm{H}, \mathrm{s}) .20, \mathrm{mp}$ $102-103^{\circ} \mathrm{C} .21, \mathrm{mp} 95.5-97^{\circ} \mathrm{C} ; \delta_{\mathrm{C}}\left(75 \mathrm{MHz} ; \mathrm{CDCl}_{3}\right) 183.3(\mathrm{~d})$, $180.8(\mathrm{~s}), 149.9(\mathrm{~s}), 147.8(\mathrm{~s}), 140.3(\mathrm{~s}), 135.0(\mathrm{~d}), 133.5(\mathrm{~d}), 132.8$ (d), 128.1 (d), 126.9 (d). 22, $\mathrm{mp} 111-112^{\circ} \mathrm{C} .23, \mathrm{mp} 84-86^{\circ} \mathrm{C} .24$, mp $90.5-91.5^{\circ} \mathrm{C} .26, \delta_{\mathrm{H}}\left(200 \mathrm{MHz} ; \mathrm{CDCl}_{3} ; J / \mathrm{Hz}\right) 7.46(1 \mathrm{H}, \mathrm{d}$, $J 1.9), 7.34-7.30(7 \mathrm{H}, \mathrm{m}), 6.98(1 \mathrm{H}, \mathrm{dd}, J 3.6,1.6), 6.68(1 \mathrm{H}, \mathrm{d}$, $J 10.7), 6.24(1 \mathrm{H}, \mathrm{d}, J 10.7), 6.05(1 \mathrm{H}, \mathrm{d}, J 1.9), 4.05(2 \mathrm{H}, \mathrm{s}) .28$,
$\delta_{\mathrm{H}}\left(200 \mathrm{MHz} ; \mathrm{CDCl}_{3} ; J / \mathrm{Hz}\right) 7.41(1 \mathrm{H}, \mathrm{d}, J 1.9), 7.33-7.29$ $(5 \mathrm{H}, \mathrm{m}), 7.18(2 \mathrm{H}, \mathrm{dd}, J 6.6,2.0), 6.87(2 \mathrm{H}, \mathrm{dd}, J 6.6,2.0), 6.66$ $(1 \mathrm{H}, \mathrm{d}, J 10.5), 6.25(1 \mathrm{H}, \mathrm{d}, J 10.5), 5.92(1 \mathrm{H}, \mathrm{d}, J 1.9), 4.03(2 \mathrm{H}$, s), $3.78(3 \mathrm{H}, \mathrm{s})$.

\section{Acknowledgements}

We thank the National Science Council for financial support (Grant NSC84-2113-M002-010).

\section{References}

1 I. Wender, R. Levine and M. Orchin, J. Am. Chem. Soc., 1950, 72, 4375.

2 O. Črvinka, P. Maloň and H. Procházková, Collect. Czech. Chem. Commun., 1974, 39, 1869.

3 W. S. Emerson and T. M. Ratrick, J. Org. Chem., 1949, 14, 790; H. T. Clarke and E. E. Dreger, Org. Synth., 1941, Coll. Vol. I, 304.

4 M. Gomberg and W. E. Bachmann, J. Am. Chem. Soc. 1927, 49 , 236; M. R. Kegelman and E. V. Brown, J. Am. Chem. Soc., 1953, 75, 5961 .

5 E. V. Kryukova and A. P. Tomilov, Elektrokhimiva, 1969, 5, 869 (Chem. Abstr., 1969, 71, 76739j).

6 W. G. Blenderman and M. M. Joullié, Tetrahedron Lett., 1979, 4985; W. G. Blenderman and M. M. Joullié, Synth. Commun., 1981, 11, 881.

7 D. N. Kursanov, Z. N. Parnes, G. I. Bolestova and L. I. Belen'kii, Tetrahedron, 1975, 31, 311.

8 J.-S. Shiue, C.-C. Lin and J.-M. Fang, Tetrahedron Lett., 1993, 34, 335 .

9 J.-S. Shiue and J.-M. Fang, J. Chem. Soc., Chem. Commun., 1993, 1277.

10 D. L. Comins and M. O. Killpack, J. Org. Chem., 1987, 52, 104; D. L. Comins, Synlett, 1992, 615

Paper 5/05895C Received 6th September 1995 Accepted 7th September 1995 